\title{
ALIH WAHANA CERITA RAKYAT TERJADINYA PULAU BALI DARI BUKU CERITA BERGAMBAR MENJADI ANIME
}

\author{
Silvia Damayanti, Ni Putu Luhur Wedayanti, Ida Ayu Laksmita Sari \\ Program Studi Sastra Jepang Fakultas Ilmu Budaya Universitas Udayana \\ Telp: o83119841381,E-mail: silvia_damayanti@unud.ac.id
}

\begin{abstract}
Abstrak
Penelitian ini mengkaji alih wahana cerita rakyat Bali yang berjudul Terjadinya Pulau Bali dari buku cerita bergambar menjadi anime. Objek penelitian ini adalah cerita rakyat Bali Terjadinya Pulau Bali karya Yuliadi Soekardi (2004) dan Anime Legenda Selat Bali karya Evelyn Zhang (2010). Penelitian ini dianalisis secara kualitatif dengan teori Alih Wahana Damono (2012) dan teori Strukturalis. Penelitian ini bertujuan untuk mengetahui cara alih wahana cerita rakyat Bali dari buku cerita bergambar menjadi anime dan meningkatkan ketertarikan dan kecintaan masyarakat Bali terhadap cerita rakyat Bali. Hasil penelitian yaitu bahwa sebagai sarana pelestarian cerita rakyat, penulis cerita anime Legenda Selat Bali dalam proses alih wahana dari buku cerita bergambar melakukan pengurangan, penambahan, dan pemvariasian unsur-unsur intrinsik pembentuk cerita rakyat Terjadinya Pulau Bali. Pengurangan, penambahan, dan pemvariasian tersebut dilakukan untuk menyesuaikan dengan bentuk dan jenis anime yang dibuat. Anime Legenda Selat Bali diperuntukkan bagi anak-anak oleh karena itu, terdapat pengurangan pada tokoh cerita, alur dan peristiwa, dan latar. Pengurangan ini dilakukan untuk menyerderhanakan cerita. Selain itu, penyesuaian dilakukan dengan menghilangkan beberapa adegan kekerasan. Penambahan cerita terdapat pada adegan anti klimaks. Perubahan bervariasi terdapat pada bentuk perjudian yang dilakukan tokoh Manik dari perjudian dengan dadu menjadi sabung ayam. Simpulan penelitian ini adalah bahwa pengurangan, penambahan, dan perubahan bervariasi dalam cerita dilakukan pengarang agar cerita lebih menarik, manambah unsur penasaran, dan agar para pembaca tidak bosan.
\end{abstract}

Kata kunci: alih wahana, cerita rakyat, buku bergambar, anime

\section{PENDAHULUAN}

Sebagai salah satu media pelestarian, alih wahana merupakan bentuk tranformasi dari wahana yang satu ke wahana yang lain, dari berbagai jenis karya seni, ke karya seni lain. Alih wahana bisa terjadi dari cerita rekaan diubah menjadi bentuk tari, drama, atau film. Bukan hanya itu, alih wahana juga dapat terjadi dari film menjadi novel. Bahkan, puisi yang lahir dari lukisan atau lagu dan sebaliknya [1]. Fenomena alih wahana atau bentuk karya sastra menjadi bentuk yang lain ini sudah dilakukan sejak dulu. Seperti cerita
Ramayana yang telah dialihwahanakan dari prosa ke dalam film, drama, puisi, dan lain sebagainya.

Di Bali pelestarian cerita rakyat melalui alih wahana belum mendapat perhatian yang serius. Sebagian besar dari masyarakat yang tahu cerita rakyat Bali diperoleh dari dongeng yang disampaikan orang tua, buku bacaan, dan pelajaran yang disampaikan di sekolah. Buku-buku yang berisi cerita rakyat Bali masih susah didapatkan dan bila ada buku cerita tidak dikemas dengan menarik, berisi sedikit gambar dan kata-kata yang sangat panjang, sehingga pembaca, khususnya anak-anak kurang tertarik untuk membaca. Hal ini mengaki- 
batkan tidak semua masyarakat Bali mengetahui dan memahami cerita rakyat Bali yang mengandung nilai-nilai tradisi budaya Bali. Oleh sebab itu, tidak dapat dipungkiri bahwa satu kontribusi kekurangtahuan masyarakat Bali tentang cerita rakyat Bali berdampak pada kurangnya masyarakat Bali memahami nilai-nilai tradisi budaya Bali.

Fahmi (2015) dalam penelitiannya "Transformasi Sastra: Geliat Ekranisasi" membahas tranformasi karya sastra novel ke dalam film yang sedang marak dilakukan saat itu. Penelitian Fahmi menggunakan metode fenomenoogi yang diangkat dari ketertarikan masyarakat umum terhadap film. Hasil yang diperoleh bahwa ekranisasi menjadi salah satu strategi belajar yang efektif. Kesulitan siswa dalam memahami sebuah novel dapat dijembatani dengan ekranisasi dan dekranisasi. Ekranisasi yang dilakukan dari novel ke film dapat meningkatkan minat baca pada remaja, khususnya pada siswa SMA. Maraknya diskusi film dari transformasi novel, membuktikan geliat ekranisasi tidak hanya persoalan visual tetapi pada pesan yang disampaikan antara sutradara dan pengarang. Penelitian ekranisasi yang dilakukan Fahmi merupakan bagian dari alih wahana, yaitu alih wahana dari novel ke film (ekranisasi). Walaupun objek penelitian berbeda, namun penelitian Fahmi dijadikan dasar pemikiran penelitian [2]. Penelitian Fahmi (2015) dijadikan pijakan bahwa alih wahana adalah sarana yang tepat dan efektif dalam pelestarian cerita rakyat.

Dengan mengetahui pentingnya pelestarian cerita rakyat sebagai salah satu media penanaman karakter masyarakat dan bangsa maka penelitian ini akan membahas alih wahana cerita rakyat di Bali sebagai upaya pelestarian cerita rakyat dengan menggunakan teori Alih Wahana, Teori Strukturalis. Penelitian ini bertujuan untuk mengetahui upaya pelestarian cerita rakyat upaya pelestarian dan peyebarluasan cerita rakyat di Bali.

\section{METODE PENELITIAN}

Penelitian ini dilakukan secara kualitatif menggunakan pendekatan komperatif. Pengumpulan data dalam penelitian ini menggunakan metode ke- pustakaan (library research dengan adalah teknik catat, yaitu mencatat hal atau temuan data yang dijadikan model analisis data dalam buku bergambar cerita rakyat Terjadinya Pulau Bali karangan Yuliadi Soekardi (2004) dan anime berjudul Legenda Selat Bali karya Evelyn Zhang (2010). Setelah data terkumpul, data diklasifikasi berdasarkan proses perubahan yang terjadi akibat alih wahana, yaitu proses penciutan, penambahan, dan perubahan variasi.

Data yang telah diklasifikasikan dianalisis dengan metode deskriptif analitik dan metode formal. Metode deskriptif analisis ini dilakukan dengan cara mendeskrisipkan fakta-fakta yang disusul dengan analisis. Cara kerja metode deskriptif analisis tidak semata menggambarkan, tetapi juga memberikan pemahaman dan penjelasan secukupnya. Metode deskriptif analisis bisa digabungkan dengan metode formal[3]. Mula-mula data dideskripsikan dengan maksud untuk menemukan unsur-unsurnya pembentuk cerita rakyat dalam buku cerita rakyat dan komik dengan mengunakan teori struktural, kemudian dibandingkan dengan menggunakan teori alih wahana Damono (2005) dengan menggunakan metode komperatif untuk menemukan perubahan unsur pembentuk certia rakyat. Hasil analisis disajikan secara informal, yaitu melalui kata-kata, kalimat, dan bentuk-bentuk narasi yang lain.

\section{Sinopsis Cerita Terjadinya Pulau Bali}

Pada zaman dahulu saat daratan Pulau Jawa dan Pulau Bali masih menyatu, hiduplah seorang pendeta yang termasyur bernama Ki Sidi Mantra dan anaknya Manik Angkeran. Ia mengajar muridmurid dari berbagai daerah di padepokannya yang terletak di negeri Daha daratan Pulau Jawa. Dikisahkan beberapa murid Ki Sidi Mantra yang saat itu berguru di padepokan, yaitu Surya, Bomantara, Jaka, Palguna, dan Manik Angkeran. Hampir semua muridnya mampu melaksanakan dharmanya dan mengikuti ajaran gurunya, tetapi ada pula yang menyimpang, salah satunya adalah Manik Angkeran. Ki Sidi Mantra sangat menyayangi dan memanjakan Manik Angkeran, anak semata wayang, yang ditinggal oleh ibunya ketika dilahirkan. 
Kasih sayang Ki Sidi Mantra menjadikan Manik Angkaran berkepribadian buruk. Ia hobi berjudi dan arogan. Ia karap berjudi secara diamdiam dibelakang Sidi Mantra. Walaupun sudah diperingkatkan oleh saudara perguruannya, ia tetap berjudi. Ki Sidi Mantra akhirnya mengetahui perbuatan anaknya dan melarang perjudian di Desa Papar karena meresahkan warga desa. Manik Angkeran tidak juga mau berubah, tergiur dengan harta yang didapat secara singkat, ia pun tetap melakukan perjudian di Desa Wangom hingga menyebabkan ia terlilit hutang yang banyak.

Hutang Maniktidak hanya membuat Manikyang susah namun Sidi Mantra dan orang-orang yang berada di Padepokan juga ikut menanggungnya, pasalnya orang-orang bayaran di tempat perjudian tersebut melakukan tindakan kekerasan dan menyerang Padepokan agar Manik mau melunasi hutangnya. Karena tidak tahan dengan itu semua, Sidi Mantra akhirnya meminta bantuan kepada Naga Basuki di lereng Gunung Agung. Dengan menggunakan genta pemberian orang tua berambut putih saat Manik lahir, Ki Sidi Matera menemui Naga besuki. Naga Basuki dengan baik hati membantu Sidi Mantra dengan mengeluarkan emas dari sisik kulit naganya. Pertolongan hanya dapat dilakukan sekali dan dengan syarat dipakai untuk melunasi hutang.

Hutang pun lunas, tetapi Manik Angkeran berjudi lagi. Bahkan habisnya semua harta benda peninggaan Ibunya yang membuat Ki Sidi Mantera turun tangan dengan meminta bantuan kepada Naga Basuki pun tidak membuat Manik Angkeran jera. Ia melakukan kesalahan itu lagi. Sidi Mantra yang sudah meminta bantuan kepada Naga Basuki mengutus Manik agar menemui Naga Basuki seorang diri. Namun apa daya, Manik yang silau akan harta, memotong ujung ekor Naga Basuki yang berisikan berlian yang cantik dan membuat Naga Basuki sangat murka sehingga mengurungnya di Gua Selamangleng yang panas.

Mendengar hal itu Sidi Mantra menemui Naga Basuki untuk meminta maaf dan memasang kembali ekor Naga Basuki yang sempat dipotong oleh Manik. karena kebaikan Sidi Mantra, Naga Basuki membebaskan Manik. Sidi Mantra akhirnya berpikir, sifat Manik tidak akan berubah jika ia kembali pulang dengannya ke negeri Daha maka dengan persetujuan Naga Basuki, Sidi Mantra memisahkan dataran Gunung Agung dengan dataran di negeri Daha. Sidi Mantra menggambar garis lurus dengan tongkatnya lalu dari garis tersebut keluarlah air dan dua dataran itu terpisah. Manik Angkeran, Naga Basuki dan Naga Kecil yaitu murid dari Naga Basuki tinggal di dataran Gunung Agung yang sekarang disebut dengan Bali, sedangkan Sidi Mantra tinggal di dataran negeri Daha yang sekarang dikenal dengan Pulau Jawa. Dengan demikian Sidi Mantra dapat pulang dengan tenang karena Manik tidak akan pernah bisa ke negeri Daha. Manik dibimbing oleh Naga Basuki agar sifatnya berubah, karena Sidi Mantra sudah tidak dapat membimbing Manik.

\section{Sinopsis Cerita Legenda Selat Bali}

Pada zaman dahulu Jawa dan Bali adalah satu pulau .Saat itu hidup seorang brahmana yang sakti dan baik hati bernama Mpu Bekung dengan anaknya Manik Angkeran.Manik Angkeran gemar berjudi dan sering kalah. Akibatnya ia berhutang banyak sekali dan akhirnya meminta tolong kepada ayahnya. Mpu Bekung merasa kasihan kepada anak yang sangat dicintainya tetapi harta yang dimilikinya telah habis untuk membayar hutang judi Manik Angkeran sebelumnya. Mpu Bekung pun memcari cara dan meminta petunjuk dari para Dewa. Suatu hari Dewapun memberi petunjuk agar Mpu Bekung pergi ke Gunung Agung untuk menemui Naga Besakih.

Diam-diam Manik Angkeran mengikuti Mpu Bekung yang pergi dengan membawa genta ke Gunung Agung. Manik Angkeran melihat ayahnya memohon bantuan. Naga Besakih pun membantu Mpu Bekung dengan memberikan harta dari sisiknya. Manik Angkeran yang tamak takjub melihat ayahnya menerima harta yang banyak dengan mudah. Ia pun pulang diam-diam sebelum ketahuan ayahnya. Setelah membayar semua hutangnya, Manik Angkeran yang masih memiliki sisa uang pun berjudi lagi dan kembali berhutang. Suatu hari, Manik Angkeran mencuri genta milik ayahnya, kemudian menemui Naga Besakih untuk 
meminta bantuan agar diberikan harta. Naga Besakih membantu Manik Angkeran, tetapi pada saat Naga ingin pergi, Manik melihat permata bersar di ekor Naga Besakih. Ia pun memotong ekor Naga Besakih. Manik Angkeran melarikan diri, namun dengan kesaktiannya Naga membakar Manik Angkeran menjadi abu.

Mpu Bekung mengetahui bahwa anaknya telah tiada akibat kejahatan anaknya sendiri. Ia meminta maaf kepada Naga Besakih dan memohon agar anaknya dihidupkan kembali. Naga Besakih menyanggupi permintaan tersebut dengan syarat Mpu Bekung harus dapat menyambungkan kembali ekornya. Dengan kesakitiannya Mpu Bekung mengembalikan ekor Naga dan memindahkan permata ke mahkota Naga. Mpu Bekung pun diberi gelar Sidi Mantera yang berarti Brahmana yang sangat Sakti. Akhirnya Manik Angkeran dihidupkan kembali. Manik Angkeranpun memohon ampun kepada Naga Besakih. Kemudan, Mpu Bakung meminta Naga menerima Manik sebagai muridnya supaya ia dapat belajar kebajikan dan kehidupan dari Naga Besakih. Naga Besakih menyanggupi dengan demikian Manik Angkeran tinggal dengan Naga Besakih dan ayahnya pulang ke Jawa. Dalam perjalannya kembali ke Jawa Sidi Mantra khawatir bahwa Manik Angkeran akan kembali puang ke Jawa dan berjudi maka dengan kesaktiannya ia mengeluarkan air dari bawah tanah dan menjadikannya laut yang memisahkan Jawa dengan Bali laut itu kemudian diberi nama selat Bali

\section{Alih Wahana Cerita Rakyat "Terjadinya Pulau Bali” dari Buku Bergambar Menjadi Anime "Legenda Selat Bali"}

Alih wahana cerita Cerita Rakyat Terjadinya Pulau Bali dari Buku Bergambar Menjadi Anime Legenda Selat Bali dipaparkan berdasarkan unsur-unsur intrinsik pembentuk karya sastra berupa tema, tokoh dan penokohan, alur, latar, dan sudur pandang. Berikut paparan alih wahana Cerita Rakyat Terjadinya Pulau Bali dari Buku Bergambar Menjadi Anime Legenda Selat Bali.

\section{Tema}

Menurut Stanton tema adalah makna yang dikandung oleh sebuah cerita[4]. Tema cerita rakyat dalam buku bergambar Terjadinya Pulau Bali dan anime Legenda Selat Bali tidak mengalami perubahan, kedua cerita memiliki tema yang sama, yaitu asal usul Selat Bali. Baik dalam buku cerita rakyat dan anime mengisahkan tentang terjadinya Selat Bali, bahwa Selat Bali terbantuk karena kesaktian yang dimiliki Sidi Mantra yang khawatir bahwa Manik Angkeran akan kembali ke Negeri Daha atau Jawa maka dengan tongkatnya ia mengeluarkan air dari tanah dan jadilah laut yang memisahkan Jawa dengan Bali. Laut itu kemudian diberi nama selat Bali

\section{Penokohan}

Penokohan merujuk tokoh dan perwatakan tokoh. Tokoh merupakan pelaku cerita yang melakukan berbagai aksi dan peristiwa yang ditimpakan kepadanya. Sedangkan perwatakan tokoh adalah kualifikasi mental dan fisik yang dimiliki oleh tokoh cerita yang membedakan antara satu tokoh dengan tokoh lain dalam cerita[4]. Pada proses alih wahana Cerita Rakyat Terjadinya Pulau Bali dari buku bergambar menjadi anime Legenda Selat Bali terjadi perubahan dalam penokohan, yaitu terjadi penyempitan atau pengurangan tokoh.

Dalam cerita Terjadinya Pulau Bali di buku bergambar terdapat dua puluh tiga tokoh, yaitu terdiri atas Ki Sidi Mantra dan Manik Angkeran sebagai tokoh utama. Sedangkan tokoh tambahan utama adalah murid padepokan yang terdiri atas Jaka Sengara, Bomantara, Surya, dan Palguna. Selain itu, terdapat tokoh Pak Lurah, Jagabaya, dan kelima orang yang membantu Pak Lurah. Ki Wulung, Bondan (orang suruhan Ki Wulung), Para warga, Seorang petani, Endang Arga, Pak Kawituwo, Bandar, Bu Sumi, Gento, belasan Anak buah Gento, Seorang tua berambut putih, Naga Kecil, dan Naga Basuki.

Sedangkan tokoh dalam anime Legenda Selat Bali hanya terdapat dua tokoh utama Mpu Bekung dan Manik Angkeran, dan tokoh tambahan Naga Besakih dan penduduk desa yang menagih hutang judi Manik Angkeran.

Pada buku bergambar, jumlah tokoh lebih banyak dari pada anime. Hal ini disebabkan karena 
cerita dalam buku bergambar alur cerita lebih kompleks. Banyaknya tokoh sampingan dalam buku cerita bergambar membuat cerita semakin menarik karena seiring banyaknya tokoh yang muncul membuat konflik pada cerita semakin memanas. Sedangkan pada versi anime, tokoh hanya dimunculkan sebanyak tiga orang yang merupakan tokoh utama saja kerena durasi yang terbatas dan memudahkan penonton, khususnya penonton anak-anak dalam memahami cerita.

Tokoh-tokoh yang terdapat pada buku bergambar dan anime memiliki sifat yang sama hanya saja penggambaran fisiknya yang sedikit berbeda, salah satu contohnya adalah tampilan pakaian setiap tokoh dalam cerita. Dalam buku bergambar para tokoh digambarkan mengenakan pakaian tradisional Bali, sedangkan dalam anime para tokoh digambarkan mengenakan baju pendeta agama Hindu. Walaupun adanya penciutan pada tokoh sampingan pada anime, namun alur secara keseluruhan tidak terpengaruh. Berikut data gambar tokoh dalam buku cerita bergambar dan anime.

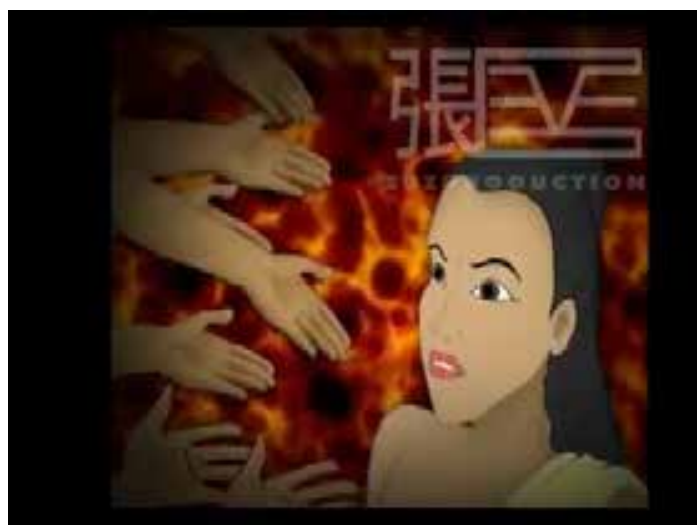

Gambar 1. Tokoh Manik sedang berkelahi

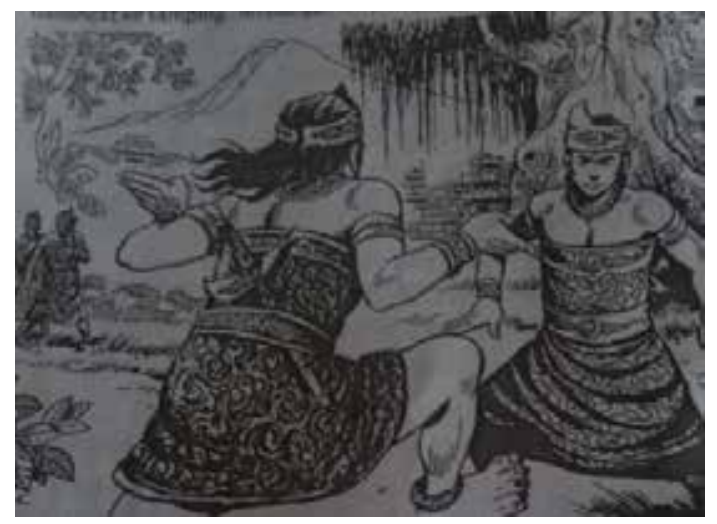

Gambar 2. Tokoh Manik dililit hutang

\section{Alur}

Menurut Lukens alur merupakan tingkah laku tokoh dalam aksinya yang diperlihatkan dalam urutan kejadian. Alur membuat segala sesuatu yang dikisahkan bergerak dan terjadi [4]. Dalam buku cerita bergambar Terjadinya Pulau Bali yang terdiri atas 126 halaman ini, alur peristiwa disajikan dengan kompleks, penuh dengan konflik, dan urutan peristiwa tidak dikisahkan secara progresif linier dan runtut (alur maju), tetapi dikisahkan dengan teknik sorot-balik (flash-back).

Kekompleksan cerita pada buku bergambar Terjadinya Pulau Bali ditandai dengan banyaknya tokoh tambahan dalam cerita seperti yang telah di bahas pada 3.2.2 di atas dan aksi yang ditampilkan dalam balutan konflik-konflik yang melanda tokoh utama. Konflik-konflik yang dialami oleh tokoh utama berupa konflik batin dan konflik eksternal dengan tokoh lainnya membuat cerita menarik dan menegangkan. Bahkan konflik terjadi dari awal cerita, yaitu pada tahap perkenalan karakter tokoh utama, Manik Angkeran, yang gemar berjudi dan berkarakter arogan. Manik Angkeran berkelahi dengan teman seperguruannya yang melaporkan tentang kegiatan berjudi yang dilakukannya di desa kepada Ayahnya, Ki Sidi Mantera[5].

Sedangkan teknik sorot balik pada buku cerita bergambar Terjadinya Pulau Bali dikisahkan dua kali. Sorot balik yang pertama pada perkenalan perwatakan tokoh Manik Angkeran yang manja melalui kenangan masa lalu tokoh Ki Sidi Mantra. yang tidak bisa memiliki anak selama sepuluh tahun dan kehilangan ibu saat dilahirkan. Sorot balik selanjutnya terdapat pada peristiwa kenangan tokok Ki Sidi Mantra saat menerima genta dari tokoh kakek berambut putih yang dipakainya untuk menemui Naga Besuki.

Berikut runtutan peristiwa dalam buku cerita bergambar Terjadinya Pulau Bali. 


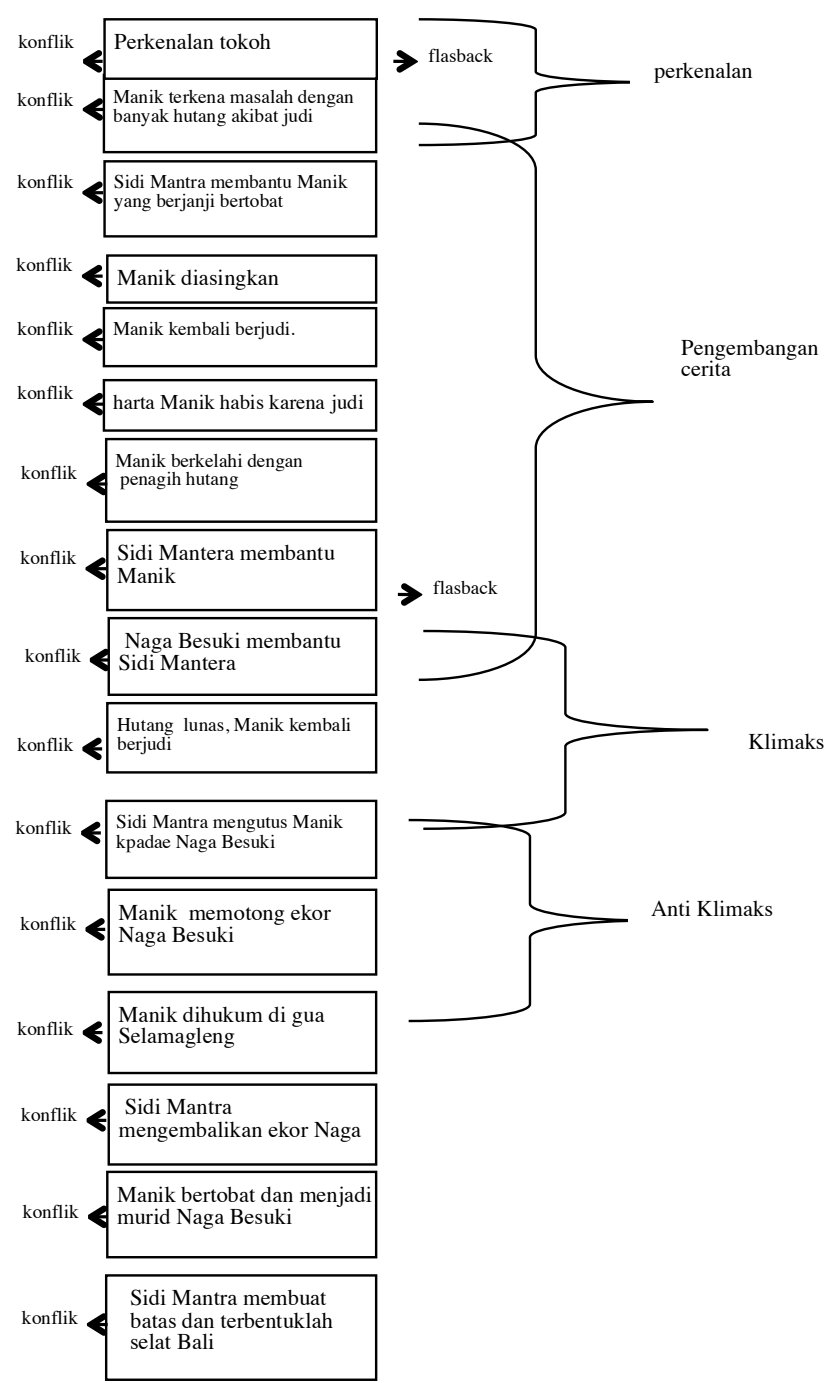

Bagan 1. Alur pada Buku Bergambar Terjadinya Pulau Bali

Pada proses alih wahana menjadi Anime Legenda Selat Bali terjadi pengurangan dan perubahan bervariasi pada beberapa peristiwa pembentuk cerita. Dalam anime Legenda Selat Bali yang berdurasi 7 menit 21 detik ini alur peristiwa disajikan menjadi lebih sederhana, tidak kompleks dan disajikan dengan teknik sorot balik. Kesederhanaan cerita dalam anime Legenda Selat Bali tampak sedikitnya peristiwa dan konflik yang dialami keempat tokoh, yaitu Mpu Bekung, Manik Angkaran, Naga Besakih, dan para penduduk. Konfikterjadidua kali, yaitu konflikeksternal antara Manik Angkaran dengan penduduk desa pada saat Manik Angkaran ditangih hutang judi dan konflik eksternal Manik Angkaran dengan Naga Besakih pada saat Manik Angkaran memotong ekor Naga Besakih. Berikut bagan alur Legenda Selat Bali.

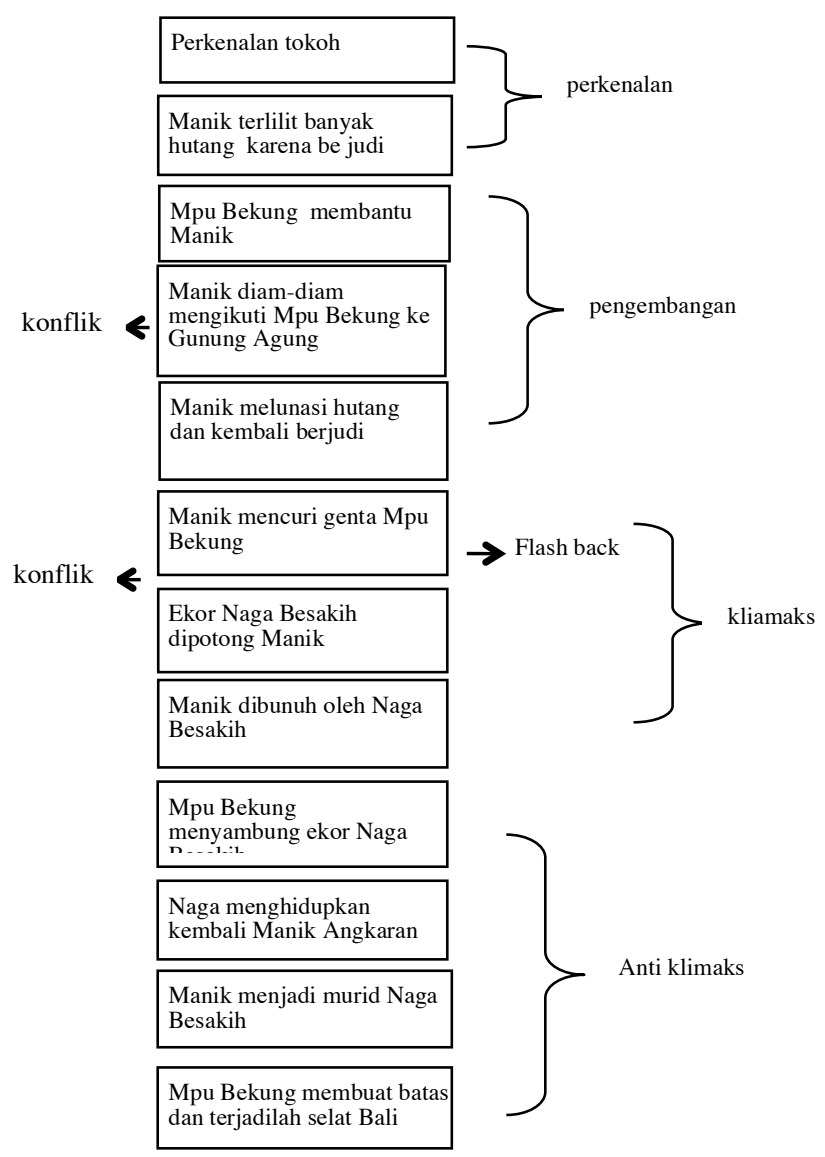

Bagan 2. Alur pada Buku Bergambar Legenda Selat Bali

Pada proses alih wahana menjadi Anime Legenda Selat Bali perubahan bervariasi Perubahan didapati pada adegan perjudian dan peristiwa pendeta Sidi Mantra (Mpu Bekung) dengan Naga Besuki (Naga Besakih) di Gunung Agung, dan kematian Manik Angkaran. Pada adegan perjudian yang dilakukan oleh Manik Angkeran dalam buku bacaan dengan menggunakan dadu (hlm 26), sedangkan dalam anime objek perjudian yang dilakukan adalah metajen (sabung ayam) (oo:34). Perubahan dilakukan untuk menyesuaikan budaya Bali yang biasanya dilakukan dengan metajen (sabung ayam). Berikut data gambar peristiwa perjudian dalam buku bergambar dan anime. 


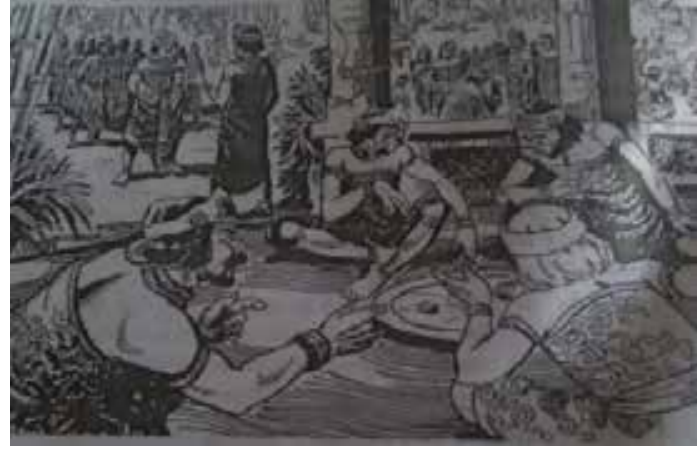

Gambar 3. Judi dadu

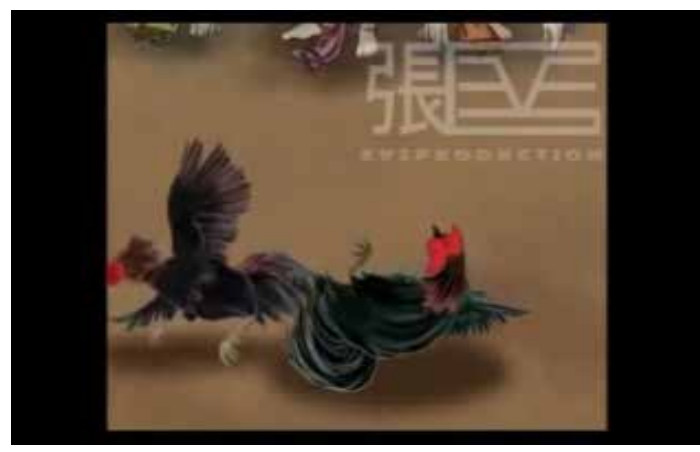

Gambar 4. metajen (sabung ayam)

Perubahan bervariasi selanjutnya peristiwa ketika pertama kali Manik ingin bertemu Naga Basuki. Pada versi anime, Manik mencuri lonceng (genta) yang terdapat di kamar Mpu Bekung. Ia mencurinya ketika Mpu Bekung sedang terlelap tidur. Sedangkan dalam versi buku bergambar, Sidi Mantra menyuruh Manik menemui Naga Basuki karena Sidi Mantra sudah sangat malu menemui Naga Basuki untuk kesekian kalinya hanya untuk meminta bantuan karena perjudian Manik (hlm 103). Selain itu, perubahan bervariasi juga terdapat pada peristiwa hukuman yang diterima oleh Manik Angkaran karena memotong ekor Naga Basuki (Naga Besakih), pada buku bergambar Manik Angkeran dihukum dengan memasukkan ke Selamangleng (batu menggantung) agar merasakan panasnya uap yang keluar dari Kawah Gunung Agung, sedangkan dalam animasi Naga Besakih membunuh Manik Angkaran dengan semburan api. Setelah Mpu Bekung memohon ampun dan menyambungkan kembali ekor Naga Besakih, Manik Angkeran pun dihidupkan kembali. Perubahan bervariasi ini dibuat oleh penulis anime agar cerita lebih menarik.

\section{Latar}

Pada proses alih wahana menjadi Anime Legenda Selat Bali tidak terjadi perubahan latar suasana yang begitu berbeda, tetapi terjadi penyempitan latar tempat yang cukup signifikan. Latar tempat dalam buku bergambar yang menampilkan 22 (dua puluh dua) latar tempat, seperti : Padepokan di negeri Daha dataran pulau Jawa, Kebun belakang Padepokan, Pinggir kebun belakang Padepokan, Rumah Pak Lurah di desa Papar, Tempat perjudian di Desa Papar, Desa Papar, Ruang tengah Padepokan, Perpustakaan Padepokan, Desa Wangon, Rumah Bondan di Desa Wangon, Halaman rumah Pak Kawituwo Desa Wangon, Kamar di rumah Bondan Desa Wangon, Kamar-kamar Padepokan, Warung nasi Bu Sumi, Desa Daha, Gua di kaki Gunung Agung, Dataran daerah Bali, Ruangan khusus di Padepokan, Di depan pintu masuk Gua Gunung Agung, Ruang depan kamar Sidi Mantra, Padepokan, Desa Daha, Sanggar Padepokan, Gua kecil dekat dengan gua tempat Naga Basuki, lereng gunung Agung dataran Bali, Pohon beringin di lereng Gunung Agung, dan Gua Selamangleng. Sedangkan dalam anime latar tempat terdiri atas negeri Daha-Jawa, tempat berjudi, lereng gunung agung, kamar Mpu Bekung, dan Pulau Jawa dan pulau Bali. Latar-latar yang banyak dihilangkan dalam versi anime karena pada latar dalam buku bergambar merupakan latar tambahan yang mendukung cerita, sedangkan dalam versi anime yang hanya menampilkan pokok cerita tidak memerlukan latar tambahan.

\section{KESIMPULAN}

Dari hasil analisis di atas dapat disimpulkan bahwa sebagai sarana pelestarian cerita rakyat, penulis cerita anime Legenda Selat Bali dalam proses alih wahana dari buku cerita bergambar melakukan pengurangan, penambahan, dan pemvariasian unsur-unsur intrinsik pembentuk cerita rakyat Terjadinya Pulau Bali.

Pengurangan, penambahan, dan pemvariasian tersebut dilakukan untuk menyesuaikan dengan bentuk dan jenis anime yang dibuat. Anime Legenda Selat Bali diperuntukkan bagi anak-anak 
oleh karena itu, terdapat pengurangan pada tokoh cerita, alur dan peristiwa, dan latar. Pengurangan ini dilakukan untuk menyerderhanakan cerita. Selain itu, penyesuaian dilakukan dengan menghilangkan beberapa adegan kekerasan. Penambahan cerita terdapat pada adegan anti klimaks. Perubahan bervariasi terdapat pada bentuk perjudian yang dilakukan tokoh Manik dari perjudian dengan dadu menjadi sabung ayam. Perubahan tersebut dilakukan pengarang agar cerita lebih menarik, manambah unsur penasaran, dan agar tidak mebosankan.

\section{UCAPAN TERIMAKASIH}

Ucapan terimakasih kepada pihak-pihak yang mendukung penulisan makalah, khususnya kepada Rektor Universitas Udayana atas dana penelitian Hibah Unggulan Program Studi dengan dana PNBP melalui LPPM dan Fakultas Ilmu Budaya Universitas Udayana Dengan Surat Perjanjian Penugasan Pelaksanaan Penelitian Nomor : 1443/ $\mathrm{UN} 14.1 / \mathrm{LT} / \mathrm{SPK} / 2016$.

\section{REFERENCES}

[1] Damono, Sapardi Djoko (2005). Pegangan Penelitian Sastra Bandingan. Jakarta: Pusat Bahasa

[2] Fahmi (2015). Sisba Seminar Internasional Sastra Bandung 2015 (Editor:Mediawati Mamat Mustaffa): Sastra Kita Kini, Dulu, dan Nanti. "Transformasi Sastra: Geliat Ekranisasi"

[3] Ratna, Nyoman Kutha (2004) Teori, Metode, dan Teknik Penelitian Sastra dari Srukturslisme hingga Poststrukturalisme Perspektif Wacana Naratif. Yogkarta: Pustaka Pelajar

[4] Nurgiantoro, Burhan (2010). Sastra Anak Pengantar Pemahaman Dunia Anak. Yogyakarta: Gadjah Mada University Press.

[5] Soekardi, Yuliadi (2004). Terjadinya Pulau Bali (Kisah Manik Angkeran). Bandung. Pustaka Setia 